\title{
Handgrip strength as a screening assessment for functional limitations
}

\author{
Alyssa K. Braun ${ }^{1 \dagger}$, Meghan E. Hess ${ }^{1 \dagger}$, Uriel Ibarra-Moreno ${ }^{1 \dagger}$, Megan D. Salvatore ${ }^{2}$ and Nathan W. Saunders ${ }^{3 *}$
}

*Correspondence: Saundenw@mountunion.edu

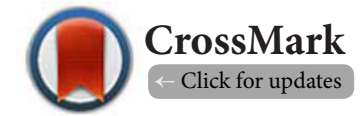

'These authors contributed equally to this work.

'Department of Human Performance and Sport Business student, University of Mount Union, USA.

${ }^{2}$ Department of Physical Therapy faculty, University of Mount Union, USA.

${ }^{3}$ Department of Human Performance and Sport Business faculty, University of Mount Union, USA.

\begin{abstract}
Background: There appears to be an undisputed strong relationship between isometric handgrip strength (HGS) and functional fitness test performance, ability to perform activities of daily living (ADLs), and mortality, but the extreme diversity in how HGS data are interpreted make it difficult to utilize the assessment in a meaningful way. The present study aimed to simplify this interpretation by establishing a single and meaningful universal HGS cutoff that would inform the test administrator whether or not additional functional fitness testing was warranted. It was hypothesized that subjects scoring above the HGS cutoff would self-report fewer functional limitations, compared with subjects scoring below the cutoff. It was also hypothesized that subjects scoring above the HGS would perform better on each functional fitness test outcome, compared with subjects scoring below the cutoff.

Methods: Male ( $\mathrm{n}=24$; Age $=62.3 \pm 14.3$ years) and female $(\mathrm{n}=59$; Age $=64.7 \pm 13.0$ years) subjects were recruited to take part in the Steps Taken Against Neuromuscular Decline (STAND) Initiative, a longitudinal study of aging. The present study is a cross-sectional assessment of the baseline data from the first 83 subjects. Subjects self-reported their perceived ability to complete the variety of ADLs included in the Composite Physical Function Scale (maximum score of 24 indicating no perceived functional limitations). They additionally completed a battery of functional fitness assessments, which included HGS, 30-s Chair Stand, 8-ft Up-and-Go, $10 \mathrm{lb}$ and $25 \mathrm{lb}$ lift and carry, and $400 \mathrm{~m}$ Walk Test. A self-developed cell phone application was utilized to produce more outcomes, such as steady-state gait speed and cadence during the $400 \mathrm{~m}$ Walk Test. Independent samples $t$-tests were used to compare the perceived and actual functional fitness outcomes between subjects with grip strength $<30 \mathrm{~kg}$ and those with grip strength $\geq 30$ $\mathrm{kg}$. Additionally, positive predictive value (PPV) and negative predictive value (NPV) were calculated to investigate the accuracy of a $30 \mathrm{~kg}$ HGS cutoff to identify subjects with perceived functional limitations (indicated by a CPF Scale score <24) or actual functional limitations (indicated by scoring below 2 standard deviations from the mean of the reference group, subjects with HGS $\geq 30 \mathrm{~kg}$ ).

Results: Subjects with a HGS $\geq 30 \mathrm{~kg}$ scored significantly higher on the CPF Scale, compared with subjects with a HGS $<30 \mathrm{~kg}(23.9+/-$ vs. 22.4+/-3.3, respectively). Likewise, subjects with a HGS $\geq 30 \mathrm{~kg}$ performed significantly better on every functional fitness test outcome, compared with subjects with a HGS $<30 \mathrm{~kg}$. The NPV (true negative) was excellent $(\geq 90 \%)$ for all outcomes, while the PPV (true positive) was poor ( $\leq$ $56 \%)$ for all outcomes.

Conclusions: A HGS $\geq 30 \mathrm{~kg}$ appears to be an appropriate cutoff to accurately rule out current functional limitations in males and females 40 years of age and older, but it is not suitable to accurately identify individuals with current functional limitations. It is suggested that individuals with a HGS $<30 \mathrm{~kg}$ undergo additional functional tests to identify any limitations that may exist.
\end{abstract}

Keywords: Senior Fitness Test, 30-s Chair Stand, 8-ft Up-and-Go, 400 m Walk Test, gait assessment, older adults, activities of daily living, self-efficacy 
Braun et al, Physical Therapy and Rehabilitation 2018,

http://www.hoajonline.com/journals/pdf/2055-2386-5-16.pdf

doi: $10.7243 / 2055-2386-5-16$

\section{Introduction}

Measures of functional fitness and self-reported ability to engage in activities of daily living (ADLs) are often used in isolation, or in combination with other exams and inventories, to either classify patients as frail or to predict the onset of disability. These functional fitness measures are relatively easy to administer, with little equipment, space, or training of testers $[1,2]$. Such measures can be used for early identification of functional decline, for example in patient populations that are known to have progressive strength decreases over time, as in cancer [3], dementia [4], Parkinson's Disease [5], and in chronic diseases such as cardiovascular disease or respiratory disease [6]. The results can then be communicated across the continuum of healthcare settings, from community fitness centers or hospital health fair screenings to healthcare providers in clinical settings to allow for timely intervention.

Among those markers, isometric handgrip strength (HGS) has received a lot of attention because of its feasibility. HGS has consistently been shown to be significantly correlated with other functional fitness tests like the Timed Up-and-Go [7-9], the assessment of gait speed [8-11], and chair stand $[8,11,12]$. Additionally, HGS has been shown to be strongly linked to self-reported health and fitness [3,11,13-18], selfreported physical activity level $[16,19]$, as well as cognitive performance [4,20-22]. Perhaps most significant is the ability of HGS to predict mortality $[6,11,22-24]$.

Several HGS cutoffs have been proposed as a risk threshold based on tertiles/quartiles/quintiles of the study population $[6,14,17,19]$, a percentage score of a reference population $[11,25]$, one standard deviation below the reference population mean [23,24], $10 \mathrm{~kg}$ increments [13], national organization recommendations [9], or other normative data [3]. Steiber et al. [24] went further to establish HGS risk thresholds for age groupings, stratified by gender and height. In contrast, many others presented evidence of a correlation between HGS and other strength tests [7], balance assessments [7,14,22,26], frailty scales [11], cognitive tests $[\mathbf{7 , 2 0 , 2 1 ]}$, and nutritional analyses [11]; however, none have indicated a cutoff that can be practically applied.

While there appears to be an undisputed strong relationship between HGS and functional fitness test performance, ability to perform ADLs, and mortality, the extreme diversity in how HGS data are interpreted make it difficult to utilize the assessment in a meaningful way. Similar to the process of risk stratification used for hypertension and Type 2 Diabetes Mellitus, the present study aimed to simplify this interpretation by establishing a single and meaningful universal HGS cutoff that would inform the test administrator whether or not additional functional fitness testing was warranted. It was hypothesized that subjects scoring above the HGS cutoff would self-report fewer functional limitations, compared with subjects scoring below the cutoff. It was also hypothesized that subjects scoring above the HGS would perform better on each functional fitness test outcome, compared with subjects scoring below the cutoff.

\section{Methods \\ Subjects}

Subjects 40 years of age and older were recruited to take part in the Steps Taken Against Neuromuscular Decline (STAND) Initiative, a longitudinal study of aging approved by the University of Mount Union Institutional Review Board. The present study is a cross-sectional assessment of the baseline data from the first 83 subjects (Table 1). Following an informed consent process, each subject self-reported their perceived ability to perform ADLs, and then underwent anthropometric and fitness testing. Only $17 \%$ of male and $24 \%$ of female subjects reported a diagnosed or known health problem that limited their physical activity, and the majority of male (88\%) and female (76\%) subjects reported that they engaged in at least 2 days of 30 minutes of continuous physical activity per week. So, despite a third of all subjects reporting high blood pressure controlled with medication, over $50 \%$ taking at least one prescription medication, and $43 \%$ reporting a fall in the past six months, the majority of subjects in this study were relatively fit and independent.

Table 1. Subject characteristics.

\begin{tabular}{lllll}
\hline & \multicolumn{2}{c}{$\begin{array}{c}\text { Male } \\
(\mathbf{n = 2 4})\end{array}$} & \multicolumn{2}{c}{$\begin{array}{c}\text { Female } \\
(\mathbf{n = 5 9 )}\end{array}$} \\
\hline & Mean & SD & Mean & SD \\
\hline Age $(\mathrm{yr})$ & 62.3 & 14.3 & 64.7 & 13.0 \\
Height $(\mathrm{m})$ & 1.79 & 0.08 & 1.60 & 0.08 \\
Weight $(\mathrm{kg})$ & 92.2 & 16.8 & 72.7 & 18.7 \\
BMI $\left(\mathrm{kg} / \mathrm{m}^{2}\right)$ & 28.9 & 5.1 & 28.4 & 7.6 \\
Waist:Hip & 0.94 & 0.07 & 0.82 & 0.10 \\
\hline
\end{tabular}

Note. BMI = Body Mass Index

\section{Composite Physical Function Scale and Activities of} Daily Living

During the interview portion of the test session, perceived level of functional abilities was measured using the self-reported Composite Physical Function (CPF) Scale [1], an instrument that validly assesses functional ability and exhibits excellent test-retest reliability $(r=0.94)$ [2].

This 12-item questionnaire asks about basic ADLs (e.g. bathing, dressing), as well as instrumental ADLs (e.g. vigorous household activities, recreational sport). Each question can be answered in three different ways; "Can do on own without help $=2$,"' $C$ an do with help $=1$," and "Cannot do $=0$." Subjects can then be classified into levels of physical function according to the totality of their responses. Those who perceived they could perform all 12 items independently attained the maximum score of 24.

\section{Anthropometric tests}

Height was measured (barefoot) using a wall-mounted tape 
Braun et al, Physical Therapy and Rehabilitation 2018,

measure. Standing against the wall facing out, subjects were asked to inhale deeply and hold while the investigator positioned a clipboard on top of the subject's head. Weight was measured (barefoot) with a portable digital scale. With subjects standing comfortably (feet approximately $10 \mathrm{~cm}$ apart), hip circumference was measured as the maximal circumference of the hip/proximal thigh, just below the gluteal fold. Finally, waist circumference was measured as the horizontal circumference of the narrowest region of the torso between the umbilicus and xiphoid process.

\section{Functional fitness tests}

Isometric handgrip strength (HGS) was assessed using a digital handgrip dynamometer (Camry EH101), which has demonstrated excellent test-retest reliability $(\mathrm{r}=0.993)$, and has been shown to be highly correlated $(r=0.987)$ with a Jianmin handgrip strength meter [27]. A very strict protocol was utilized to ensure standardization among the sample. The subject remained seated with an erect spine. They held the dynamometer in their dominant hand (their writing hand), with their shoulder completely adducted, elbow flexed at 90 degrees, and radioulnar joint in a neutral position. The grip was adjusted such that their proximal interphalangeal joints wrapped completely around the handle, index finger was at 90 degrees while it rested on the handle, and their thumb pointed vertically. The subject was instructed to squeeze the dynamometer with maximum force and hold it for 1-2 seconds. Two trials were performed and the greatest measurement was recorded.

A $400 \mathrm{~m}$ Walk Test was used to assess dynamic balance, aerobic ability, and muscular endurance. A $20 \mathrm{~m}$ linear course was set up in a long flat hallway. The subject was instructed to walk back and forth (20 lengths) as fast as possible without running, but at a pace they felt they could sustain for the entire 400 meters. The subjects was reassured that they could terminate the test at any time, or pause to sit in a chair positioned at each end; however, the time would continue to run during such breaks. The subject was allowed to use any assistive devices for walking if needed. Prior to the test, a 2-lap familiarization trial was performed to confirm participant understood all instructions.

The $400 \mathrm{~m}$ Walk Test was assessed using a self-developed cellular phone application. Validation of this application (a paper presently under review) revealed that its results are statistically the same as slow motion video analysis. An investigator time stamped events during the test (e.g. heel strikes, passing the dotted lines on the course) by tapping an in-app button. The application then reported average steady-state gait speed and cadence. Step length $(\mathrm{m} / \mathrm{step})$ was then calculated as $60 \mathrm{~s} / \mathrm{min}$ times gait speed $(\mathrm{m} / \mathrm{s})$ divided by cadence (steps/min). In previous work, the minimum detectable change (MDC) for steady-state gait speed and cadence during a 6 Minute Walk Test, a test very similar to the $400 \mathrm{~m}$ Walk Test, were determined to be $0.12 \mathrm{~m} / \mathrm{s}$ and 7.0 steps $/ \mathrm{min}$, respectively [28].
The battery of fitness assessments also included tests that are commonly utilized in clinical settings. The 30-s Chair Stand test required the subject to stand from a chair (with their arms crossed) as many times as possible in 30 seconds. For the 8 - $\mathrm{ft}$ Up-and-Go, the subject stood up from a chair, maneuvered around a cone set $8 \mathrm{ft}$ in front of the chair, and returned to the chair in an upright seated position (as quickly as possible without running). The MDC for the 30-s Chair stand and 8-ft Up-and-Go were established as 2.6 stands and $1.0 \mathrm{~s}$, respectively [28]. The $10 \mathrm{lb}$ and $25 \mathrm{lb}$ lift-and-carry tasks required the subject to lift a basket (containing $10 \mathrm{lbs}$ and then $25 \mathrm{lbs}$ ) from a chair, pivot to carry the basket around a cone set $8 \mathrm{ft}$ in front of the chair, and return the basket to the chair (as quickly as possible without running). While the test-retest reliability of the lift and carry tasks was not investigated, it used the same $8 \mathrm{ft}$ course as the 8-ft Up-and-Go, and it is therefore likely to exhibit a similar MDC. Comprehensive instructions, a demonstration, and a familiarization trial were given before all tests.

\section{Statistical analyses}

All statistical analyses were performed using SPSS version 24 (IBM Corp, Armonk, NY).

Multiple linear regression was used to test for main effects of age and gender on HGS. Visual inspection of HGS plotted against all other outcomes revealed an inflection point for most independent variables at a HGS of $30 \mathrm{~kg}$, below which functional fitness test performance declined for many subjects. Independent samples $t$-tests were used to compare the perceived and actual functional fitness outcomes between subjects with grip strength $<30 \mathrm{~kg}$ and those with grip strength $\geq 30 \mathrm{~kg}$. No correction for multiple $t$-tests was used, as the hypotheses regarding the relationship between HGS and each outcome were independent of each other. Positive predictive value (PPV), and negative predictive value (NPV) were calculated to investigate the accuracy of a $30 \mathrm{~kg} \mathrm{HGS}$ cutoff to identify subjects with perceived functional limitations (indicated by a CPF Scale score $<24$ ) or actual functional limitations (indicated by scoring below 2 standard deviations from the mean of the reference group, subjects with $\mathrm{HGS} \geq 30 \mathrm{~kg}$ ). Significance for all statistical tests was established a priori at alpha $=0.05$.

\section{Results}

\section{Handgrip strength and age}

The regression analysis revealed significant effects of age and gender on HGS, with HGS being greater in males than females at any given age but declining linearly with age in both males and females (Figure 1). There was also a significant interaction between age and gender. Males in this study exhibited about a $0.48 \mathrm{~kg}$ decrease in HGS per year, compared with $0.23 \mathrm{~kg}$ per year for females.

\section{Composite physical function scale}

The CPF Scale is a 12-item inventory of a person's perceived 
ability to perform ADLs. The maximum score attainable is 24 , so any total score $<24$ indicates that the person has difficulty with or is unable to perform at least one of the activities. The CPF Scale total score was plotted against HGS for the purposes of calculating PPV and NPV (Figure 2). A cutoff for HGS was established at $30 \mathrm{~kg}$, a round number near the breakpoint in the graph. Many subjects with a grip strength $<30 \mathrm{~kg}$ scored a perfect 24 on the CPF Scale (i.e., false positive), resulting in a poor PPV (29\%). However, only two subjects with a grip strength $\geq 30 \mathrm{~kg}$ reported a difficulty completing one or more activities on the CPF Scale (false negative), resulting in a good NPV (90.5\%). An independent samples $t$-test showed that subjects with a HGS $\geq 30 \mathrm{~kg}$ scored significantly higher on the CPF Scale, compared with subjects with a HGS $<30 \mathrm{~kg}$ (23.9+/-vs.22.4 +/- 3.3, respectively) (Table 2 ).

\section{Functional fitness tests}

Independent samples $t$-tests indicated that subjects with a HGS $\geq 30 \mathrm{~kg}$ performed significantly better than those with a HGS $<30 \mathrm{~kg}$ for all fitness test outcomes, except cadence (Table 2).

The results from all fitness tests and subcomponents of those tests were plotted against HGS (Figure 3). Two standard deviations below the mean performance of subjects with a HGS $\geq 30 \mathrm{~kg}$ was used as a cutoff to define a functional
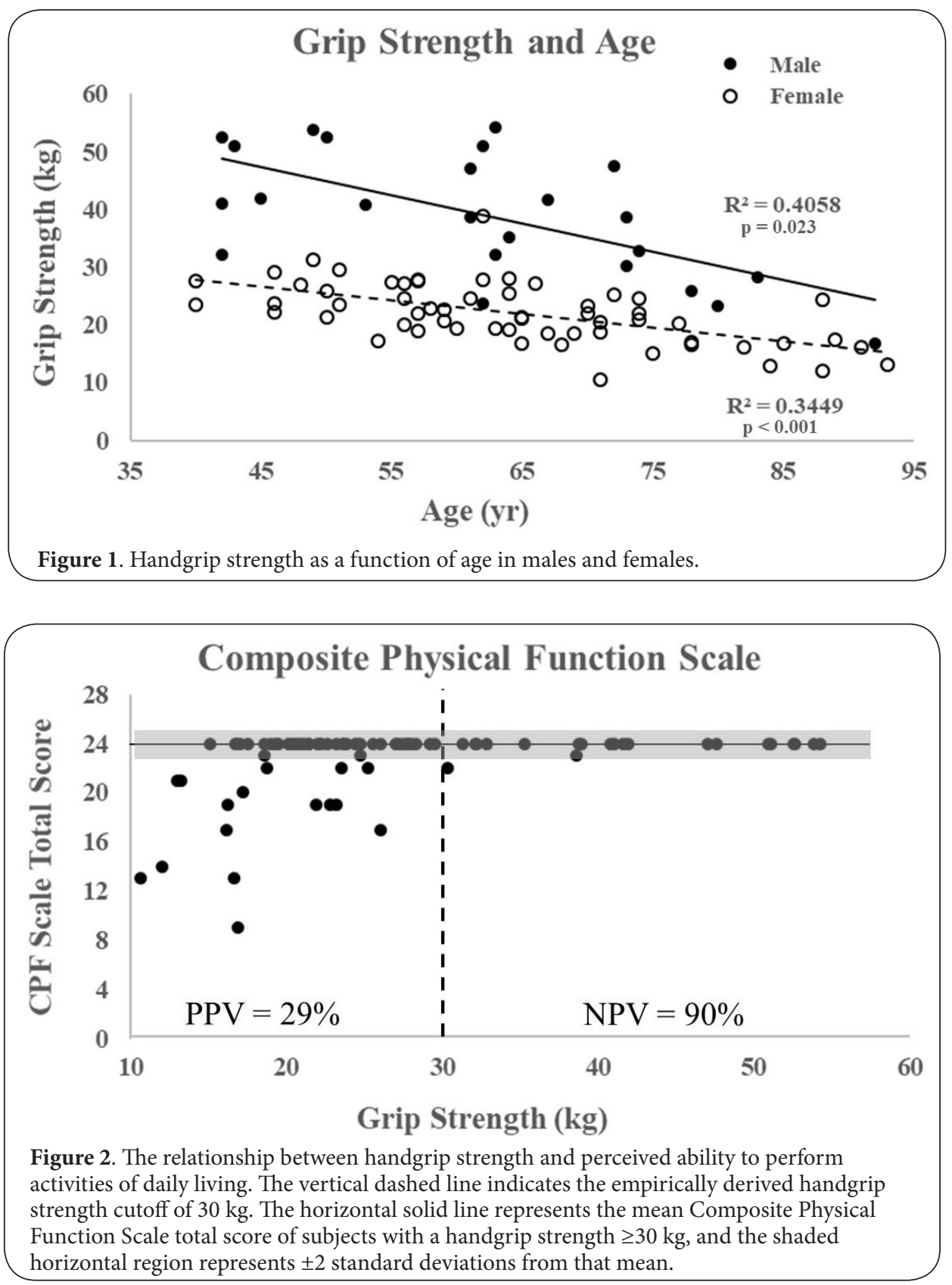
Table 2. Perceived and Actual Functional Fitness.

\begin{tabular}{|c|c|c|c|c|c|}
\hline \multirow{3}{*}{ Outcomes } & \multicolumn{4}{|c|}{ Handgrip Strength } & \multirow{3}{*}{ p-value } \\
\hline & \multicolumn{2}{|c|}{$\begin{array}{l}<30 \mathrm{~kg} \\
(\mathrm{n}=62)\end{array}$} & \multicolumn{2}{|c|}{$\begin{array}{l}\geq 30 \mathrm{~kg} \\
(\mathrm{n}=21)\end{array}$} & \\
\hline & Mean & SD & Mean & SD & \\
\hline Composite Physical Function Scale Total Score & 22.4 & 3.3 & 23.9 & 0.5 & 0.047 \\
\hline 30-s Chair Stand (\# of stands) & 11.1 & 2.4 & 12.1 & 1.7 & 0.044 \\
\hline 8-ft Up-and-Go Time (s) & 7.3 & 3.1 & 5.6 & 1.0 & 0.015 \\
\hline $10 \mathrm{lb}$ Lift and Carry Time (s) & 6.7 & 2.2 & 5.2 & 0.9 & 0.003 \\
\hline $25 \mathrm{lb}$ Lift and Carry Time (s) & 7.6 & 3.2 & 5.3 & 0.8 & 0.001 \\
\hline $400 \mathrm{~m}$ Walk Test Steady-State Gait Speed $(\mathrm{m} / \mathrm{s})$ & 1.49 & 0.36 & 1.85 & 0.28 & $<0.001$ \\
\hline $400 \mathrm{~m}$ Walk Test Steady-State Cadence (steps/min) & 130.3 & 15.4 & 132.2 & 15.1 & 0.610 \\
\hline 400 m Walk Test Steady-State Step Length (m) & 0.68 & 0.11 & 0.84 & 0.07 & $<0.001$ \\
\hline $400 \mathrm{~m}$ Walk Test Ste ady-State Step Length:Height & 0.42 & 0.06 & 0.47 & 0.04 & 0.002 \\
\hline
\end{tabular}

Note. Bold values indicate a statistically significant difference between handgrip strength groups.

limitation. The same $30 \mathrm{~kg} \mathrm{HGS}$ cutoff established for the CPF Scale was observed for all outcomes, except for steadystate cadence during the $400 \mathrm{~m}$ Walk Test (Figure 3F). The NPV (true negative) was excellent ( $\geq 90 \%$ ) for all outcomes (Figure 3A-3H), suggesting that very few subjects with a HGS $\geq 30 \mathrm{~kg}$ exhibited functional limitations. In contrast, the PPV (true positive) was poor ( $\leq 56 \%)$ for all outcomes, suggesting that many subjects with a HGS $<30 \mathrm{~kg}$ performed above the cutoff for functional limitations (i.e., were similar to the reference group).

It may be important that the PPVs for the $400 \mathrm{~m}$ Walk Test varied by outcome. The PPV for steady-state gait speed was $32 \%$, but looking at the components of gait speed separately, the PPV for cadence (3\%) was much lower, while the PPV for step length (55\%) was much greater. Even after normalizing step length to subject height (Figure $\mathbf{3 H}$ ), the PPV remained elevated at $45 \%$.

\section{Discussion}

The present study was conducted in order to gain more insight into how HGS might be used as a screening tool for functional limitations. A $30 \mathrm{~kg} \mathrm{HGS}$ cutoff was empirically identified from scatterplots of HGS vs. CPF Scale and functional fitness test results. As was hypothesized, few subjects with a HGS $\geq 30 \mathrm{~kg}$ self-reported difficulty with ADLs or performed poorly on most functional fitness test outcomes. Contrary to our hypothesis, there was no difference in cadence between HGS groupings.
Handgrip strength and age

We found that HGS was $0.48 \mathrm{~kg}$ and $0.23 \mathrm{~kg}$ lower per year increase in age in males and females, respectively. Though this relationship was statistically significant for both genders, the correlations were rather weak, with age only explaining about $40 \%$ of the variation in HGS. In a 3-year prospective study, Turusheva et al. [22] showed that HGS declined at a rate of $1.5 \mathrm{~kg} /$ year for males and 0.3-0.4 kg/year for females. In a similar study of Chinese subjects, Auyeung et al. [29] found rates of -0.8 and $-1.2 \mathrm{~kg} / \mathrm{year}$ for males and females, respectively. The age associated decline in both muscle mass and muscle strength are well documented, so it is not surprising that a decline in HGS in males and females is consistently supported. It appears that disagreement in the literature is rather in regard to the expected rate of decline. Factors such as the population studied, length of follow-up, and repeatability of testing protocols are likely to influence theses rates.

Handgrip strength and perceived functional abilities Fewer than $10 \%$ of our subjects (males and females combined) with a $\mathrm{HGS} \geq 30 \mathrm{~kg}$ self-reported one or more functional limitations. Similarly, in a much larger cross-sectional study $(n=2,956)$, Kuh et al. [14] found that only $5.9-13.2 \%$ of females with a HGS $\geq 30.6 \mathrm{~kg}$ self-reported one or more functional limitations. Even in a much smaller sample of older males and females, healthrelated quality of life was shown to be significantly greater in the group of subjects with an average HGS of $33.7 \mathrm{~kg}$, compared 

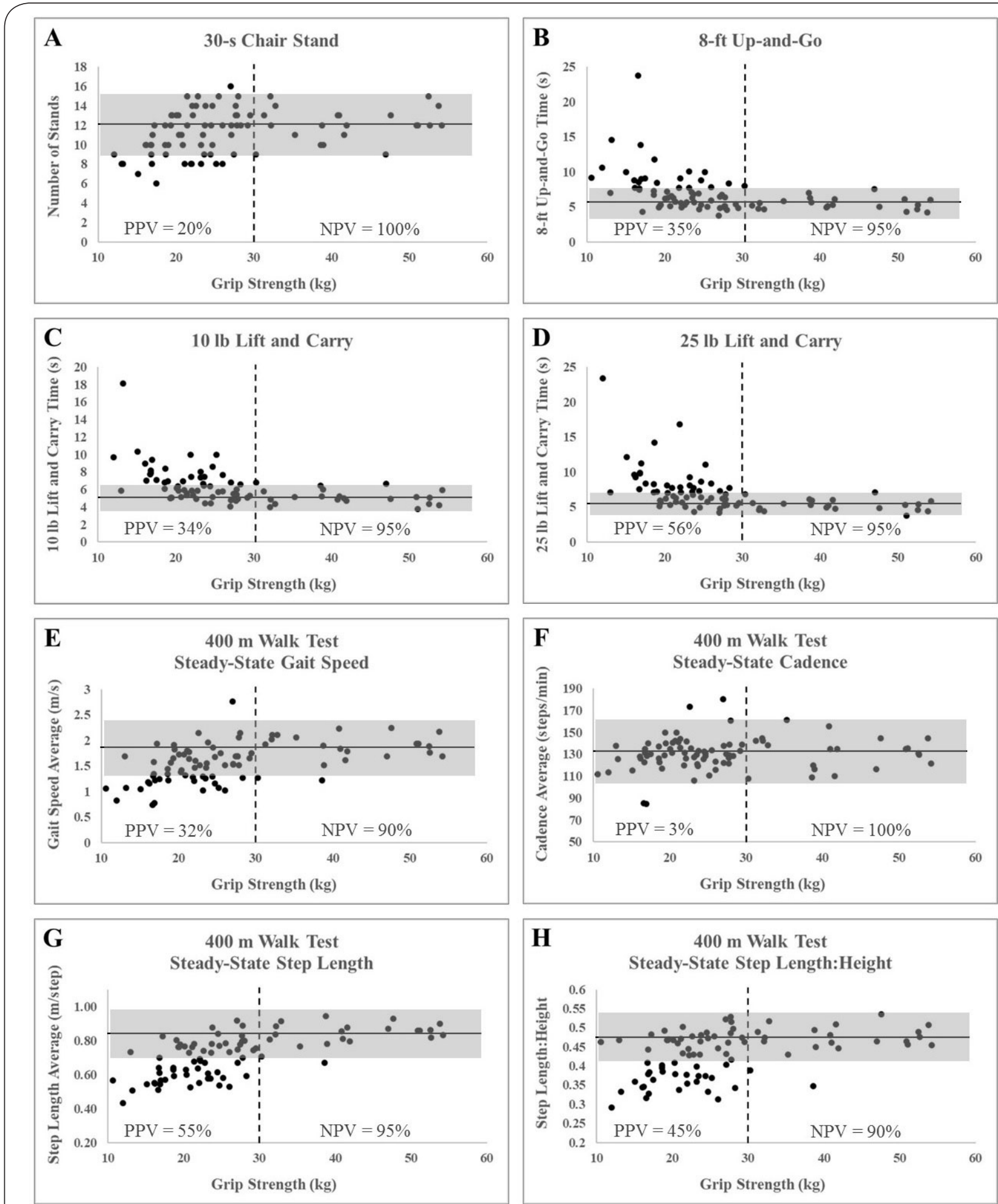

Figure 3. The relationship between handgrip strength and functional fitness test outcomes. The vertical dashed lines indicate the empirically derived handgrip strength cutoff of $30 \mathrm{~kg}$. The horizontal solid lines represent the mean performance of subjects with a handgrip strength $\geq 30 \mathrm{~kg}$, and the shaded horizontal region represents \pm 2 standard deviations from that mean. PPV=Positive Predictive Value (true positive), the percentage of subjects with a handgrip strength $<30 \mathrm{~kg}$ and a functional fitness test result more than 2 standard deviations below the mean of reference group. NPV=Negative Predictive Value (true negative), the percentage of subjects with a handgrip strength $\geq 30 \mathrm{~kg}$ and a functional fitness test performance within 2 standard deviations of the mean of the reference group. 
Braun et al, Physical Therapy and Rehabilitation 2018,

with the group of subjects with an average HGS of $27.7 \mathrm{~kg}$ [15].

In contrast, $3.7-7.2 \%$ of males with a HGS $\geq 43.6 \mathrm{~kg}$ selfreported one or more functional limitations [14], evidence that males in that study perceived functional limitations at a greater HGS. However, given that 8.6-12.2\% of males below that HGS cutoff also reported at least one functional limitation, it is entirely possible that the $30 \mathrm{~kg} \mathrm{HGS}$ cutoff utilized in the present study would have yielded a similar outcome in that cohort.

Handgrip strength and functional fitness test performance Except for HGS, all other fitness tests utilized here have a theoretical ceiling for what can be achieved, regardless of fitness. For example, subjects were instructed to complete the 8-ft Upand-Go, lift and carry tasks, and $400 \mathrm{~m}$ Walk Test as quickly as possible without running. The relatively horizontal and linear data for HGS $\geq 30 \mathrm{~kg}$ seems to represent that theoretical ceiling for each test (solid horizontal lines in Figure 3), and notably almost all individuals (young and old males and females) with a HGS $\geq 30 \mathrm{~kg}$ approached that ceiling. Conversely, rather than being a marker of sarcopenia or frailty, the fanning of the data for HGS $<30 \mathrm{~kg}$ suggests that many individuals with a HGS $<30 \mathrm{~kg}$ were unable to achieve that ceiling. While many others have reported a significant correlation between HGS and these fitness test outcomes [7-12], we believe we are the first to identify a HGS threshold where performance deviates from the theoretical ceiling.

In support of existing literature [8-11], HGS and gait speed were significantly and positively related. However, further analysis of the present data revealed that HGS was significantly associated with step length, but not cadence, during the 400 $\mathrm{m}$ Walk Test. This may suggest that a decline in gait speed primarily results from a shorter step length, rather than a slower stepping rate.

\section{Limitations}

Because of the relatively small sample size and cross-sectional design of the present study, these results should be interpreted cautiously. Unlike the relatively large longitudinal studies that have reported the risk of future disease, disability, and mortality based on baseline HGS, the $30 \mathrm{~kg} \mathrm{HGS}$ cutoff suggested here is only suitable to serve as a screen for current functional limitations.

It may also be noteworthy that we did not perform an internal test-retest reliability analysis our specific HGS or lift and carry protocols.

\section{Conclusion}

While many individuals with a HGS $<30 \mathrm{~kg}$ reported no functional limitations and also performed well on most functional fitness test outcomes (poor PPV), only a small fraction of individuals with a $\mathrm{HGS} \geq 30 \mathrm{~kg}$ reported or exhibited functional limitations (good NPV). Therefore, a HGS $\geq 30 \mathrm{~kg}$ appears to be an appropriate cutoff to accurately rule out current functional limitations in males and females 40 years of age and older, but it is not suitable to accurately identify individuals with current functional limitations. It is suggested that individuals with a HGS $<30 \mathrm{~kg}$ undergo additional functional tests to identify any limitations that may exist.

\section{Competing interests}

The authors declare that they have no competing interests.

Authors' contributions

\begin{tabular}{|l|c|c|c|c|c|}
\hline Authors' contributions & AKB & MEH & UIM & MDS & NWS \\
\hline Research concept and design & $\checkmark$ & $\checkmark$ & $\checkmark$ & $\checkmark$ & $\checkmark$ \\
\hline Collection and/or assembly of data & $\checkmark$ & $\checkmark$ & $\checkmark$ & $\checkmark$ & $\checkmark$ \\
\hline Data analysis and interpretation & $\checkmark$ & $\checkmark$ & $\checkmark$ & $\checkmark$ & $\checkmark$ \\
\hline Writing the article & $\checkmark$ & $\checkmark$ & $\checkmark$ & $\checkmark$ & $\checkmark$ \\
\hline Critical revision of the article & $\checkmark$ & $\checkmark$ & $\checkmark$ & $\checkmark$ & $\checkmark$ \\
\hline Final approval of article & $\checkmark$ & $\checkmark$ & $\checkmark$ & $\checkmark$ & $\checkmark$ \\
\hline Statistical analysis & -- & -- & -- & -- & $\checkmark$ \\
\hline
\end{tabular}

\section{Acknowledgements}

While their contributions did not warrant authorship, we would like to thank (in no particular order) Brianna Blohm, Cameron Ressel, Abigail Matsushima, Kennady Miller, Kristen Fouts, Joshua Lawhorne, Natasha Green, Alexandra Colacino, Samuel Todd, Valerie Russel, and Brianna Gassman for their integral role in designing this study and collecting data.

\section{Publication history}

Editor: Gordon John Alderink, Grand Valley State University, USA. Received: 28-Aug-2018 Final Revised: 27-Sept-2018

Accepted: 21-Oct-2018 Published: 31-Oct-2018

\section{References}

1. Rikli RE and Jones CJ. Functional fitness normative scores for community-residing older adults, ages 60-94. J Aging Phys Act. 1999; 7:162-181. | Pdf

2. Rikli RE and Jones CJ. Development and validation of criterionreferenced clinically relevant fitness standards for maintaining physical independence in later years. Gerontologist. 2013; 53:255-67. | Article | PubMed

3. Owusu C, Margevicius S, Schluchter M, Koroukian SM and Berger NA. Short Physical Performance Battery, usual gait speed, grip strength and Vulnerable Elders Survey each predict functional decline among older women with breast cancer. J Geriatr Oncol. 2017; 8:356-362. | Article | PubMed Abstract | PubMed FullText

4. Ong HL, Chang $\mathrm{SH}$, Abdin E, Vaingankar JA, Jeyagurunathan A, Shafie $\mathrm{S}$, Magadi H, Chong SA and Subramaniam M. Association of Grip Strength, Upper Arm Circumference, and Waist Circumference with Dementia in Older Adults of the WiSE Study: A Cross-Sectional Analysis. J Nutr Health Aging. 2016; 20:996-1001. I Article I PubMed

5. Brusse KJ, Zimdars S, Zalewski KR and Steffen TM. Testing functional performance in people with Parkinson disease. Phys Ther. 2005; 85:13441. I PubMed

6. Rantanen T, Volpato S, Ferrucci L, Heikkinen E, Fried LP and Guralnik JM. Handgrip strength and cause-specific and total mortality in older disabled women: exploring the mechanism. J Am Geriatr Soc. 2003; 51:636-41. | Article | PubMed

7. Alonso AC, Ribeiro SM, Luna NMS, Peterson MD, Bocalini DS, Serra MM, Brech GC, Greve JMD and Garcez-Leme LE. Association between handgrip strength, balance, and knee flexion/extension strength in older adults. PLoS One. 2018; 13:e0198185. | Article | PubMed Abstract I PubMed FullText 
Braun et al, Physical Therapy and Rehabilitation 2018,

8. Coelho-Junior HJ, Rodrigues B, Goncalves IO, Asano RY, Uchida MC and Marzetti E. The physical capabilities underlying timed "Up and Go" test are time-dependent in community-dwelling older women. Exp Gerontol. 2018; 104:138-146. | Article | PubMed Abstract | PubMed FullText

9. Merchant RA, Banerji S, Singh G, Chew E, Poh CL, Tapawan SC, Guo YR, Pang YW, Sharma M, Kambadur R and Tay S. Is Trunk Posture in Walking a Better Marker than Gait Speed in Predicting Decline in Function and Subsequent Frailty? J Am Med Dir Assoc. 2016; 17:65-70. | Article | PubMed

10. Fragala MS, Alley DE, Shardell MD, Harris TB, McLean RR, Kiel DP, Cawthon PM, Dam TT, Ferrucci L, Guralnik JM, Kritchevsky SB, Vassileva MT, Gudnason V, Eiriksdottir G, Koster A, Newman A, Siggeirsdottir K, Satterfield S, Studenski SA and Kenny AM. Comparison of Handgrip and Leg Extension Strength in Predicting Slow Gait Speed in Older Adults. J Am Geriatr Soc. 2016; 64:144-50. | Article | PubMed Abstract | PubMed FullText

11. Hernandez-Luis R, Martin-Ponce E, Monereo-Munoz M, Quintero-Platt G, Odeh-Santana S, Gonzalez-Reimers E and Santolaria F. Prognostic value of physical function tests and muscle mass in elderly hospitalized patients. A prospective observational study. Geriatr Gerontol Int. 2018; 18:57-64. | Article | PubMed

12. van Lummel RC, Evers J, Niessen M, Beek PJ and van Dieen JH. Older Adults with Weaker Muscle Strength Stand up from a Sitting Position with More Dynamic Trunk Use. Sensors (Basel). 2018; 18. | Article | PubMed Abstract | PubMed FullText

13. Gopinath B, Kifley A, Liew $G$ and Mitchell P. Handgrip strength and its association with functional independence, depressive symptoms and quality of life in older adults. Maturitas. 2017; 106:92-94. | Article | PubMed

14. Kuh D, Bassey EJ, Butterworth S, Hardy R and Wadsworth ME. Grip strength, postural control, and functional leg power in a representative cohort of British men and women: associations with physical activity, health status, and socioeconomic conditions. J Gerontol A Biol Sci Med Sci. 2005; 60:224-31. | PubMed

15. Musalek $C$ and Kirchengast S. Grip Strength as an Indicator of HealthRelated Quality of Life in Old Age-A Pilot Study. Int J Environ Res Public Health. 2017; 14. | Article | PubMed Abstract | PubMed FullText

16. Rantanen T, Guralnik JM, Sakari-Rantala R, Leveille S, Simonsick EM, Ling $S$ and Fried LP. Disability, physical activity, and muscle strength in older women: the Women's Health and Aging Study. Arch Phys Med Rehabil. 1999; 80:130-5. | Pdf | PubMed

17. Rantanen T, Guralnik JM, Foley D, Masaki K, Leveille S, Curb JD and White L. Midlife hand grip strength as a predictor of old age disability. JAMA. 1999; 281:558-60. | Article | PubMed

18. Sallinen J, Stenholm S, Rantanen T, Heliovaara M, Sainio P and Koskinen $S$. Hand-grip strength cut points to screen older persons at risk for mobility limitation. J Am Geriatr Soc. 2010; 58:1721-6. | Article | PubMed Abstract | PubMed FullText

19. Cooper A, Lamb M, Sharp SJ, Simmons RK and Griffin SJ. Bidirectional association between physical activity and muscular strength in older adults: Results from the UK Biobank study. Int J Epidemiol. 2017; 46:141-148. | Article | PubMed Abstract | PubMed FullText

20. Ramnath U, Rauch L, Lambert EV and Kolbe-Alexander TL. The relationship between functional status, physical fitness and cognitive performance in physically active older adults: A pilot study. PLoS One. 2018; 13:e0194918. | Article | PubMed Abstract | PubMed FullText

21. Taekema DG, Gussekloo J, Maier AB, Westendorp RG and de Craen AJ. Handgrip strength as a predictor of functional, psychological and social health. A prospective population-based study among the oldest old. Age Ageing. 2010; 39:331-7. | Article | PubMed

22. Turusheva A, Frolova $E$ and Degryse JM. Age-related normative values for handgrip strength and grip strength's usefulness as a predictor of mortality and both cognitive and physical decline in older adults in northwest Russia. J Musculoskelet Neuronal Interact. 2017; 17:417-432. | Pdf | PubMed Abstract | PubMed FullText

23. Rosero-Bixby L and Dow WH. Predicting mortality with biomarkers: a population-based prospective cohort study for elderly Costa Ricans.
Popul Health Metr. 2012; 10:11. | Article | PubMed Abstract | PubMed FullText

24. Steiber N. Strong or Weak Handgrip? Normative Reference Values for the German Population across the Life Course Stratified by Sex, Age, and Body Height. PLoS One. 2016; 11:e0163917. | Article | PubMed Abstract | PubMed FullText

25. Lee L, Patel T, Costa A, Bryce E, Hillier LM, Slonim K, Hunter SW, Heckman $G$ and Molnar F. Screening for frailty in primary care: Accuracy of gait speed and hand-grip strength. Can Fam Physician. 2017; 63:e51-e57. | Article | PubMed Abstract | PubMed FullText

26. Stevens PJ, Syddall HE, Patel HP, Martin HJ, Cooper C and Aihie Sayer A. Is grip strength a good marker of physical performance among community-dwelling older people? J Nutr Health Aging. 2012; 16:76974. | Article | PubMed

27. Chen $X$, Lu $Y$ and Zhang J. Intervention study of finger-movement exercises and finger weight-lift training for improvement of handgrip strength among the very elderly. International Journal of Nursing Sciences. 2014; 1:165-70. | Article

28. D Salvatore,Megan, M Colacino,Alexandra, E Hess,Meghan, W Todd,Samuel, W Saunders, Nathan. Concurrent validity and minimum detectable change of Senior Fitness Test components: instrumented vs. manual assessment. 2017.

29. Auyeung TW, Lee SW, Leung J, Kwok T and Woo J. Age-associated decline of muscle mass, grip strength and gait speed: a 4-year longitudinal study of $\mathbf{3 0 1 8}$ community-dwelling older Chinese. Geriatr Gerontol Int. 2014; 14 Suppl 1:76-84. | Article | PubMed

\section{Citation:}

Braun AK, Hess ME, Ibarra-Moreno U, Salvatore MD and Saunders NW. Handgrip strength as a screening assessment for functional limitations. Phys Ther Rehabil. 2018; 5:16. http://dx.doi.org/10.7243/2055-2386-5-16 